\title{
DO MASERENNE MIYAVYE AO ENTERRO CRISTÃO: NARRATIVAS DA MORTE PALIKUR-ARUKWAYENE
}

\author{
ZÉLIA MARTINS ${ }^{1}$ \\ UNIFAP, BRASIL \\ https://orcid.org/0000-0001-7385-0119
}

IRABETE MARTINS ${ }^{2}$

UNIFAP, BRASIL

https://orcid.org/0000-0002-8489-0527

VINÍCIUS COSMOS BENVEGNÚ ${ }^{3}$

UFAM, BRASIL

http://orcid.org/0000-0002-4288-8269

\begin{abstract}
RESUMO: Este artigo tem como escopo os ritos funerários do povo Palikur-Arukwayene da região do Rio Urucauá no extremo norte do Brasil. Resultado de um trabalho etnográfico, são apresentadas narrativas históricas e míticas sobre a morte e o processo funerário, desde os antigos enterros secundários em urnas de argila, até a incorporação de ritos e práticas cristãs. As transformações e ressignificações relacionadas à morte, por sua vez, desvelam o longo processo histórico do contato colonial entre os Palikur-Arukwayene e as sociedades de matriz euro-ocidentais. Ademais, este é um experimento narrativo, justamente porque busca conciliar conhecimentos e vozes heterogêneas, pois é escrito por duas acadêmicas indígenas Palikur-Arukwayene e um autor não indígena. Assim, há uma sobreposição de desafios como por exemplo, diferenças de gênero, assimetrias de conhecimentos, heteroglosia e implicações éticas. Por fim, destaca-se que o registro dessas narrativas e conhecimentos tem importância para o diálogo e discussões acadêmicas, mas principalmente para as jovens gerações Palikur-Arukwayene.
\end{abstract}

PALAVRAS-CHAVE: Palikur-Arukwayene, Morte, Rituais funerários, História indígena.

ABSTRACT: This article has as its scope the funeral rites of the Palikur-Arukwayene people of the Urucaua River region in the extreme north of Brazil. It is a result of an ethnographic work and presents historical and mythical narratives about death and the funeral process, from the ancient secondary burials in clay urns, to the incorporation of Christian rites and practices. The transformations and resignifications related to death also reveal the long historical process of colonial contact between the Palikur-Arukwayene and the Euro-Western societies. Furthermore, this is a narrative experiment, precisely because it seeks to reconcile knowledge and heterogeneous voices, as it is written by two Palikur-Arukwayene indigenous academics and a non-indigenous author. Thus, there is an overlapping of challenges such as gender differences, knowledge asymmetries, heteroglosia, and ethical implications. Finally, it is important to note that the research

\footnotetext{
${ }^{1}$ Indígena do povo Palikur-Arukwayene, Professora Indígena, graduanda em Licenciatura Intercultural Indígena pela Universidade Federal do Amapá. E-mail: martinszelia30@ gmail.com

${ }^{2}$ Indígena do povo Palikur-Arukwayene, graduanda em Licenciatura Intercultural Indígena pela Universidade Federal do Amapá. E-mail: martinsirabete@gmail.com

${ }_{3}^{3}$ Doutorando em Antropologia Social na Universidade Federal do Amazonas (PPGAS/UFAM). E-mail: vcbenvegnu@yahoo.com.br
}

MARTINS, Zélia; MARTINS, Irabete; BENVEGNÙ, Vinícius Cosmos. Do maserenne miyavye ao enterro cristão: narrativas da morte Palikur-Arukwayene. Espaço Ameríndio, Porto Alegre, v. 14, n. 2, p. 326-345, jul./dez. 2020. 
Espaço Ameríndio

of these narratives and knowledge is important for dialogue and academic discussions, but especially for the young Palikur-Arukwayene generations.

KEYWORDS: Palikur-Arukwayene, Death, Funeral Rituals, Indian History. 


\section{Introdução}

Esse artigo é resultado de uma pesquisa para o Trabalho de Conclusão de Curso de Licenciatura Intercultural Indígena, em que foi apresentado o ritual funerário do povo Palikur-Arukwayene, denominado Kayka Kisepka. Nesse artigo é apresentada a morte enquanto um evento importante dentro da organização social Palikur-Arukwayene, desde o cuidado com o corpo da pessoa falecida nos ritos fúnebres, até os rituais de enterramento e esquecimento da pessoa. A pesquisa foi realizada pelas duas autoras indígenas Palikur-Arukwayene e orientada pelo terceiro autor do presente artigo.

Diferentemente da maioria dos trabalhos acadêmicos, uma pesquisa realizada por indígenas envolve muito mais pessoas que apenas o pesquisador e suas fontes. A pesquisa indígena é realizada nas redes de parentesco. Desta forma pode-se afirmar que este é um trabalho que une e conecta várias gerações. Ele foi realizado pelas irmãs Palikur-Arukwayene Uvayan e Kwaygu, que pertencem ao clã Paraymiyano (pessoa da origem de peixe bagre), e são filhas de dona Kaguvra (Jovita Labontê, do clã Kawakiyano ou Kawayano - pessoa de origem do abacaxi) e do senhor Tavara Paraymiyene (Manoel Luiz Martins, do clã Paraymiyene - pessoa de origem do peixe bagre). Quanto ao terceiro autor, não indígena, coube a tarefa de orientação durante a elaboração da pesquisa, a indicação de leituras referentes ao tema de pesquisa, a discussão dessa bibliografia e a redação conjunta final desse texto, bem como a orientação concernente aos formatos acadêmicos exigidos. Contudo, também coube ao orientador o papel de interlocutor-aprendiz que, a partir da confiança depositada pelas pesquisadoras indígenas, pôde conhecer e aprender sobre a organização social Palikur a partir dos seus conhecimentos e mitos.

Ademais disso, os autores destacam que este é um experimento narrativo, justamente porque busca conciliar conhecimentos e vozes heterogêneas. São muitos as dificuldades que se sobrepõem - diferenças de gênero, assimetrias de conhecimentos, heteroglosia, implicações éticas - e tornaram a escrita um desafio que julgamos contribuir para a discussão corrente. Assim, as decisões tomadas para a escrita foram: escrever em uma voz neutra - e não na primeira pessoa do plural - quando se fala dos rituais, histórias e mitos Palikur a fim de não outorgar ao autor não-indígena um conhecimento próprio de uma população à qual não pertence. As discussões teóricas também foram escritas em voz neutra, devido às discussões travadas entre os três autores, durante a orientação e redação do artigo. Os momentos escritos em primeira pessoa do plural são as vozes das autoras indígenas, comentando sobre seus conhecimentos e reflexões acerca do tema aqui apresentado.

Para encerrar esta introdução, este trabalho foi pensado para ser um diálogo entre algumas das disciplinas das ciências humanas cursadas durante a formação na Licenciatura Intercultural Indígena. O resultado final 
foi um trabalho de registro histórico e etnográfico. Destaca-se que, além das publicações para que os não-indígenas conheçam o povo PalikurArukwayene, o trabalho está voltado para o uso pelo povo PalikurArukwayene como registro histórico e possível material didático. Para elaborar esse trabalho e entender um pouco mais sobre os rituais funerários Palikur-Arukwayene, foram entrevistadas sete pessoas idosas do povo Palikur-Arukwayene: dona Kaguvra (Jovita, que é mãe das autoras), dona Kusiksi (Eleono), dona Pawamnah (Matilde, que é tia das autoras), senhor Sarisi, senhor Bunet (Bonifácio), dona Agaykwa (Verônica) e o senhor Wetmin (Manoel Antonio) ${ }^{4}$. Nós pesquisadoras indígenas, durante a pesquisa constatamos que algumas das práticas que relatamos nesse trabalho estão em desuso pelos Palikur-Arukwayene, mas entendemos que é importante registrar essa história para que nós, nossos filhos, netos e futuras gerações tenham acesso aos saberes e conhecimentos que os antepassados PalikurArukwayene realizavam. Acreditamos que esta é uma forma de respeitar a história do povo Palikur-Arukwayene.

\section{O povo Palikur-Arukwayene, a guerra e a mudança no enterro de seus mortos}

\section{Os Palikur-Arukwayene: etnônimos e origens}

O termo Palikur que designa a identidade deste povo advém da palavra parikwene, do tronco linguístico Aruak. Esta é uma designação constituída do encontro colonial com as sociedades europeias ${ }^{5}$. A auto-designação coletiva dessa população é Arukwayene, "pessoas que vivem na região do Rio Arukwa (Urucauá)". No entanto, os próprios Palikur-Arukwayene reconhecem que suas identidades são múltiplas. Essas identidades referemse ao pertencimento aos subgrupos ou clãs, forma como os próprios Palikur-

\footnotetext{
${ }^{4} \mathrm{O}$ povo Palikur-Arukwayene tem um grande respeito com as pessoas mortas. Uma forma de mostrar respeito é deixar de chamar a pessoa morta pelo seu nome quando vivo. Os Palikur-Arukwayene sabem que chamar a pessoa falecida pelo seu nome irá incomodar sua gihiyakemni. Isso ocorre porque após morrer a pessoa irá morar no Pahakap. Além disso, a pessoa viva que evoca o morto pelo seu nome de vivo pode sofrer consequências terrenas. A pessoa viva pode adoecer e morrer, pois não deixa a gihiyakemni do morto descansar. A gihiyakemni do morto busca se aproximar da gihiyakemni da pessoa viva, para convencê-la e levá-la junto com ela para o Pahakap. Este processo se dá por meio dos sonhos: a pessoa viva que passa a sonhar com o falecido logo adoecerá e virá a falecer também. Para evitar a evocação direta, os Palikur-Arukwayene possuem três termos para nomear uma pessoa falecida, amekene, amekenenni para os homens; amakano, amakononni para as mulheres, ou acrescentando a partícula $\min$ ao final do nome de quando viva. $\mathrm{O}$ uso desses termos possibilita que as pessoas saibam que determinada pessoa faleceu, mesmo sem ter participado dos rituais fúnebres. Durante o processo dessa pesquisa um dos interlocutores faleceu. Por isso nesse texto invocamos o senhor Wetmin dessa forma, em respeito à sua memória e aos ensinamentos que passou às autoras.

${ }^{5}$ Em Os Pronomes Cosmológicos e o Perspectivismo Ameríndio (1996), Viveiros de Castro faz uma afirmação nesse sentido: "a maioria dos etnônimos ameríndios que passaram à literatura não são autodesignações, mas nomes (frequentemente pejorativos) conferidos por outros povos [...] Os etnônimos são nomes de terceiros, pertencem à categoria do "eles" não à categoria do "nós".
}

MARTINS, Zélia; MARTINS, Irabete; BENVEGNÙ, Vinícius Cosmos. Do maserenne miyavye ao enterro cristão: narrativas da morte Palikur-Arukwayene. Espaço Ameríndio, Porto Alegre, v. 14, n. 2, p. 326-345, jul./dez. 2020. 
Arukwayene se referem e parte da literatura histórica e antropológica também. Nesse sentido, Capiberibe (2007, p. 66) aponta que o uso do conceito de clã, no que concerne aos povos indígenas sul-americanos de floresta tropical, não é o mesmo que o destinado para sociedades africanas, na sua acepção mais estrita. Para a autora os subgrupos Palikur-Arukwayene conformam "grupos bem definidos, aos quais poderia ser aplicado o termo clã, mas sem a rigidez do conceito original [...] não parece existir um termo genérico na língua Palikur para designar os clãs" (CAPIBERIBE, 2007; p. 6667). Nesse artigo aplicar-se-á a categoria clã conforme uso dado pelas pesquisadoras indígenas.

Conforme aponta o pesquisador Palikur-Arukwayene Ailton Batista Wakavuniyene (2018), em entrevista com seu avô Kwaymin (Afonso loiô), há muitos anos atrás os Palikur-Arukwayene moravam em uma região chamada Urumewni, hoje conhecida como Amazonas. Urumewni significa "uma grande bacia onde os rios e afluente deságuam". Quando os colonizadores chegaram ao que hoje é o Brasil, a violência e perseguição fez com que essa população migrasse do alto do rio Urumewni, fugindo dos europeus, até chegar na região Wasavrik, conhecida como Uaçá. Wasavrik significa na íngua parikwakri "margem do rio com grande quantidade de açaizais". Hugues Vallot em trabalho sobre as relações entre os governos franceses (colonial e republicano) e os indígenas na Guiana Francesa, a revisar a literatura afirma,

No final do século XVII e ao longo do século XVIII, em razão dessas incursões coloniais e das tensões luso-francesas, a região do Cabo do Norte (atual estado do Amapá) virou um palco de guerra. Em consequência, conheceu um despovoamento constante, em parte compensado pela chegada de novos grupos em busca de refugio. Caso, por exemplo, de povos vindos do baixo Amazonas e do Marajó, tais como os Aruã e diversos clãs Palikur, que eram perseguidos pelas frentes portuguesas e buscaram refugio nas terras controladas pelos franceses. (VALLOT, 2017; p. 79)

A despeito da literatura produzida, gostaríamos de destacar que nem palikur tampouco arukwayene são designações inequívocas da nossa identidade, ou seja, há muitas formas de se referir a ela. Palikur em parikwakri é entendido como indígena de forma genérica. Já arukwayene é o nome dado às pessoas que vivem na região Arukwa (Urucauá), uma designação de lugar, que vem da junção de dos termos arukwa (Urucauá) e

\footnotetext{
${ }^{6}$ Em sua etnografia Capiberibe também comenta sobre a origem do povo Palikur-Arukwayene em que "seu etnônimo, está impresso uma história, na qual eles teriam sido obrigados a nascer numa terra estranha, porque haviam sido "corridos" (não é dito quem os havia "corrido") de sua terra verdadeira" (CAPIBERIBE, 2007; p. 44).

MARTINS, Zélia; MARTINS, Irabete; BENVEGNÙ, Vinícius Cosmos. Do maserenne miyavye ao enterro cristão: narrativas da morte Palikur-Arukwayene. Espaço Ameríndio, Porto Alegre, v. 14, n. 2, p. 326-345, jul./dez. 2020.
} 
yene (pessoa; gente). Dessa forma, nesse texto optamos por denominar nosso povo pelo termo Palikur-Akuwayene.

\section{Territórios Palikur-Arukwayene}

Atualmente o povo Palikur-Arukwayene mora nas margens do Rio Urucauá, sendo a sua principal aldeia Kumenề. Este rio está dentro da Terra Indígena (TI) Uaçá, demarcada e homologada em 1992. A TI Uaçá, por sua vez está localizada na região conhecida como terras indígenas do Oiapoque, que compreende mais duas terras indígena, TI Juminã e TI Galibi, e nelas coabitam mais três povos indígenas, Karipuna, Galibi-Marworno e GalibiKali'na. Neste território encontram-se inúmeras ilhas, lagoas, campos alagados, cerrados e florestas tropicais de terra firme, que são ricos em fauna e flora, onde o povo Palikur-Arukwayene cultiva pequenas roças para a produção de farinha e seus subprodutos. O inverno é o período das chuvas e inicia com o surgimento do Kayeb, que começa a espalhar a água sobre a terra. Na sequência Tavara, Wakti, Kusuvwi eguttye, Kusuvwi butye e Wayan ${ }^{8}$ também espalham a água e enchem o campo que se torna abundante em alimentos. É nessa época que os animais aquáticos entram e se espalham pelo campo inundado. Neste período as pessoas têm mais facilidade de acesso a alimentos como: caça, pesca e frutas, que são a base da alimentação do povo Palikur-Arukwayene.

Além de viverem na TI Uaçá, parte do povo Palikur-Arukwayene foi residir em localidades do território que hoje compreende a Guiana Francesa. Os Palikur-Arukwayene tiveram os primeiros contatos com os franceses quando estes chegavam até o Rio Urucauá para comprar produtos dos Palikur-Arukwayene, como farinha de mandioca, peixes, cocares, pulseiras, colares, entre outros objetos produzidos. Essa comercialização entre os Palikur-Arukwayene e os franceses foi interrompida quando o Serviço de Proteção aos Índios (SPI) chegou no Rio Uaçá e instalou um posto de fiscalização no Encruzo, local de encontro entre os Rios Uaçá e Curipi, proibindo a entrada de franceses. O senhor Wetmin relatou que os PalikurArukwayene recebiam maus tratos na fiscalização do Encruzo. Nessa época enfrentavam sérios problemas, como ocorrência de epidemias, sem assistência de saúde, dificuldades para vender seus produtos em Saint Georges e Guiana Francesa, pois ao passar pelo Encruzo eram obrigados a terem seus barcos revistados pelos fiscais não indígenas (WAKAVUNIYENE, 2018 , p. 16). ${ }^{9}$ Esses motivos contribuíram para o deslocamento do povo Palikur-Arukwayene para o lado francês.

\footnotetext{
${ }^{7}$ Algumas famílias vivem em aldeias no limite ocidental da TI Uaçá ao longo da BR 156.

${ }^{8}$ Em As esculturas das estrelas das chuvas: astronomia do Rio Urucauá (2016), de Lesley e David Green, é possível aprofundar mais sobre essas constelações e sua relação entre a cosmologia Palikur-Arukwayene e eventos ambientais.

${ }^{9}$ Para maiores aprofundamentos desse tema conferir Keka SPI: o Narrador e o Sítio Mawihgi em BATISTA, 2019. 


\section{Organização política e social}

Conforme dito na seção anterior, o povo Palikur-Arukwayene se organiza socialmente a partir da divisão em clãs. Segundo a pesquisa de Ailton Batista Wakavuniyene (2018), no passado, o povo Palikur-Arukwayene era divido em trinta clãs, que viviam separadamente uns dos outros ao longo do território no Rio Urucauá. Cada um vivia seguindo sua cultura, seu modo de viver, se organizava politicamente conforme o interesse do grupo e tinha seu próprio líder Yhamwi (pajé). Naquele tempo as famílias PalikurArukwayene, dedicavam as atividades cotidianas para sustento da família, não existiam entre eles venda e troca e, assim, os alimentos pertenciam a todos os membros da família. Os alimentos provinham principalmente da coleta de frutas, de caça e de pesca. Consumiam bebidas wonska e dahka (caxixi). Praticavam rituais como: Turé, Maracá, Wawamnah (dança de Maracá), Sabug (dança de Tambor), Kisepka, Karawsukmam, Ukikammah, Mayemnah, entre outros.

Atualmente, restaram seis clãs Palikur-Arukwayene, que já não vivem mais espalhados uns dos outros, mas juntos em aldeias. Os outros clãs foram extintos devido à influência dos colonizadores europeus e às epidemias trazidas por eles. As línguas faladas por cada clã também eram diferentes, mas apenas os mais velhos ainda as falam. Atualmente o povo Palikur-Arukwayene fala uma única língua, que é a junção das línguas dos clãs Maykyene e Kamuwyene. Cada clã tem a sua própria marca gráfica, que é representada através das marcas corporais ou nos seus objetos como: cuia, potes, entre outros.

O senhor Sarisi, pertencente ao clã Wayveyene, morador da aldeia Maxika, juntamente com sua filha e netos, relatou que o modo de vida dos antepassados Palikur-Arukwayene era muito diferente do modo atual. Em cada aldeia havia diferentes costumes, e era completamente proibido realizarem trabalhos com os clãs diferentes. Não faziam maywuka da plantação com outros clãs, só os que pertenciam ao mesmo grupo. Mas naquele tempo o trabalho era menor do que é hoje, pois os PalikurArukwayene faziam uvuveya (farinha) e wat (beiju) somente para seu próprio sustento, e os outros alimentos eram retirados da floresta. Eram aproveitadas todas as frutas - inajá, ingá, buruti, cutiti açaí, inuvga, makanano, ukum e ximig. Esses frutos eram muito importantes para a sobrevivência do povo, por não haver os alimentos industrializados.

Para a organização das festas na aldeia, o líder se reunia com a família para definir o melhor tempo ${ }^{10}$ de preparo da bebida wonska, usada nos

\footnotetext{
${ }^{10}$ A realização das festas - como Turé, Waw e Sabug - acontece apenas no verão, entre os meses de julho e novembro, pois no período de chuvas entre os meses de dezembro a junho, não é possível realizar essas festas por conta das chuvas constantes. Além disso, eram realizadas apenas na época da lua cheia, pois naquele tempo não havia energia para iluminar a noite. As danças eram realizadas no quintal das casas. 
rituais como: as dança do Turé, dança de Wawwamnah ${ }^{11}$, dança de Sabug ${ }^{12}$, dança de Ukikamnah ${ }^{13}$ e as danças Mayemnah e Karawsukman que faziam parte do Ritual de Kayka Kisepka, entre outros rituais. As pessoas que podiam participar do ritual eram apenas do próprio clã ou de clãs convidados. Em função de conflitos espirituais, um clã tinha medo de invadir a festa de outro, ou mesmo aparecer na aldeia alheia sem ser convidado. De acordo com o senhor Sarisi, os clãs de antigamente eram muito bravos, e eles eram capazes de matar as pessoas que não estavam convidadas. Eles preparavam remédios para matar, para colocar na wonska, no mingau ou em outros alimentos servidos na festa. Eles também podiam matar pessoas através dos restos de comida, como ossos. Portanto, cada pessoa deveria cuidar bem do resto da comida para não deixar espalhado no chão. Como será apresentado abaixo, os enterros também eram e continuam sendo realizados separadamente entre os clãs.

\section{Da Guerra e Rituais funerários}

De acordo com o relato do senhor Sarisi, no passado, cada clã enterrava seus mortos dentro da sua própria aldeia, perto da casa onde morava. Sarisi explicou que antigamente o povo Palikur-Arukwayene não escolhia um local para ser cemitério, porque os antigos não enterravam os corpos em caixões de madeira. O enterro obedecia a um longo ritual funerário no qual o morto era queimado e que finalizava com uma grande festa, a Kayka Kisepka ${ }^{14}$, o enterro secundário em urnas mortuárias de argila. Hoje os Palikur-Arukwayene enterram seus mortos em caixões feitos de madeira e não queimam mais os corpos. De acordo com o relato de Pawamnah, esse costume mudou depois de terminar a guerra dos Palikur-

\footnotetext{
${ }^{11}$ A dança do Waw (maracá) começa com sua preparação pelas mulheres, que recebem ajuda de seus maridos. A dança inicia com as mulheres acompanhadas de seus waw em uma mão e na outra um bastão cerimonial, quando os homens entram na dança as mulheres repassam o waw para eles. Hoje, contudo, nem todas as mulheres sabem praticar os cantos da festa de waw, somente as mulheres idosas. Muitos anos atrás, quando uma das autoras era criança com dez anos de idade, uma festa waw e sabug foi realizada na aldeia Tawary. Lá uma senhora chamada Suwigu (nome do pássaro inambu-preto) cantou os cantos dessas danças. Depois disso os idosos não realizaram mais esse tipo de dança. Algumas causas disso referem-se à entrada das religiões cristãs nas aldeias Palikur-Arukwayene.

${ }^{12}$ A dança de Sabug (tambor) é um ritual realizado pelos homens. Os sabug são feitos de madeira, pele de macaco guariba, akuywa (cipó do mato) e são pintados com urucum. É uma dança diferente do Maracá, Turé e Kisepka. Essa dança é muito bonita, pois os responsáveis de sabug ficam na frente de uma fila, tocando os sabug e cantando as músicas, e as dançarinas, logo atrás, os acompanham cantando.

${ }^{13}$ A dança do Wawamna é uma dança realizada durante três dias na época da lua cheia, e no período do verão. Os objetos que as mulheres utilizam na festa são a saia de fibra de kuwuwta, cocar na cabeça, colar no pescoço. O banco é feito de madeira na figura de jacaré para o descanso das dançarinas.

${ }^{14}$ Era uma festa que reunia muita gente, envolvia danças, comidas, cantos, choros e tristeza. A Kayka Kisepka era o ritual para enterrar os restos mortais de uma pessoa. Logo que morria o corpo da pessoa era assado e queimado em uma fogueira feita especialmente para isso. Depois quebravam os ossos e então depositavam na urna e a guardavam em um local dentro da casa do falecido, para, após dez anos de resguardo, poderem realizar a Kayka Kisepka. Para aprofundar mais sobre essa festa, consultar Kayka Kisepka: O Ritual Funerário do Povo Palikur em, MARTINS; MARTINS, 2019.

MARTINS, Zélia; MARTINS, Irabete; BENVEGNÙ, Vinícius Cosmos. Do maserenne miyavye ao enterro cristão: narrativas da morte Palikur-Arukwayene. Espaço Ameríndio, Porto Alegre, v. 14, n. 2, p. 326-345, jul./dez. 2020.
} 
Arukwayene com os Hiyer (povo Galibi Kali'na). Ela conta que no período da guerra entre Hiyer e os Palikur-Arukwayene, na região do Rio Urucauá, apesar de muitos Palikur-Arukwayene morrerem, também mataram quase todos Hiyer e os que sobreviveram fugiram para Guiana Francesa.

Pawamnah explicou que após esse encontro os Palikur-Arukwayene foram atrás dos Hiyer até Caiena. Um tempo depois os Hiyer mandaram os mensageiros para avisar o povo Palikur-Arukwayene que eles estavam voltando e que era para os Palikur-Arukwayene se prepararem com suas armas para continuar a guerra. Quando os Hiyer voltaram, trouxeram consigo os holandeses como aliados para guerrear. Ela destacou que as guerras entre os Hiyer e os Palikur-Arukwayene sempre tinham acordos. Ela explicou que seu finado pai, Dimut, e sua esposa, Mamaday, contavam para ela que no tempo da guerra havia gestos respeitosos entre os combatentes, porque os inimigos não atacavam os outros sem avisá-lo previamente. Portanto, os ataques deveriam ser avisados e ocorrer nos dias marcados. Além disso, a guerra acontecia somente no período da lua cheia.

Pawamnah contou que houve um grande conflito entre os PalikurArukwayene e Hiyer em uma aldeia conhecida como Kwap. Este conflito, além de envolver os dois povos indígenas, teve a participação dos holandeses. Após terminado um longo e forte conflito, cada família PalikurArukwayene buscou seus mortos para passarem pelos rituais funerários. Após realizarem o maserenne 15 , os restos eram pilados e colocados dentro do mukuw $^{16}$ (urna funeraria) ${ }^{17}$. Os holandeses, após observarem os rituais funerários Palikur-Arukwayene, passaram a recriminar a forma como enterravam seus mortos, porque eles queimavam o corpo do morto na fogueira. Então, os holandeses falaram para o povo Palikur-Arukwayene que havia outra forma de fazer enterro, e ensinaram os Palikur-Arukwayene a construir o caixão de madeira e colocar o morto sem precisar queimar o corpo. A partir desse contato, segundo o relato da senhora Pawamnah, os Palikur-Arukwayene passaram a enterrar seus mortos no caixão de madeira, deixando de enterrar na forma Palikur-Arukwayene. Portanto, o enterro em caixões não é próprio do povo Palikur-Arukwayene, mas sim uma prática externa e que perdura entre os Palikur-Arukwayene.

\footnotetext{
15 Termo Parikwaki vulgarmente traduzido como “assar”. Contudo o verbo assar não abrange todas as dimensões rituais do processo.

${ }^{16}$ Mukuw/Wanamiyo são urnas funerárias, que os Palikur-Arukwayene utilizavam há muitos anos atrás para guardar os ossos dos mortos. Mukuw era usado apenas para o enterro dos homens, enquanto que a Wanamiyo era usada apenas para o enterro das mulheres. O mukuw/wanamiyo é produzido com argila e casca de uma árvore $k w e p$, que é queimada e transformada em cinzas, depois misturada com argila para confeccionar o mukuw na forma arredondada. Depois de terminar de confeccionar, é deixado secar bem para poder queimá-la com muita lenha a fim de que seja bem cozido e guardado na casa para ser usada como urna. O mukuw/wanamiyo, não pode ser produzido na hora que uma pessoa morre, porque ele demora mais dois dias para terminar sua confecção. Para ele ser queimado, espera-se o mukuw/wanamiyo secar bem para poder levá-lo ao fogo, tudo isso para não quebrar. Antigamente todas as pessoas já tinham mukuk/wanamiyo preparados em suas casas, de qualquer tamanho, pequeno, médio ou grande, para o funeral.

${ }^{17}$ Os pertences do morto eram colocados em outra urna e enterravam junto com o falecido dentro de sua aldeia. MARTINS, Zélia; MARTINS, Irabete; BENVEGNÙ, Vinícius Cosmos. Do maserenne miyavye ao enterro cristão: narrativas da morte Palikur-Arukwayene. Espaço Ameríndio, Porto Alegre, v. 14, n. 2, p. 326-345, jul./dez. 2020.
} 


\section{A morte entre os Palikur-Arukwayene}

Nessa seção trazemos uma narrativa sobre a morte entre os PalikurArukwayene. Ela está baseada nas entrevistas com o senhor Wetmin e dona Kusiksi. De acordo com os costumes dos ancestrais Palikur-Arukwayene, quando uma pessoa falecia na aldeia todos os trabalhos paravam, porque é um acontecimento que traz muita tristeza, dor, sentimentos de emoção e choro para todas as famílias e os parentes. Quando uma pessoa morria, logo se organizava um grupo que seria responsável por levar a mensagem da morte dentro da aldeia. Este grupo percorria as aldeias vizinhas e avisava as pessoas que estavam trabalhando na roça ou no mato, porque todos deveriam ser avisados que tinha acontecido um falecimento na aldeia. Os que recebiam o aviso logo largavam o trabalho e arrumavam as coisas para conferir a notícia e passavam a noite toda junto com a família daquele que faleceu.

Segundo o senhor Wetmin, o corpo da pessoa falecida deveria passar por um processo ritual de preparação para o maserenne. Após o falecimento, três pessoas da família realizavam o banho do morto. O banho era e continua sendo muito importante, pois, se não der o banho na pessoa morta, os Maygukune $^{18}$ podem usar o corpo do falecido, sendo que este pode até mesmo levantar e brigar com alguma família que ele tinha problema e que não conseguiu resolver antes de falecer. Devido a essas e outras prescrições, deve-se lavar o corpo do falecido. O preparo para o maserenne miyavye ${ }^{19}$ necessitava de dois tipos de lenha. No dia que seria o masaraki ${ }^{20}$, os homens tiravam do mato uma árvore denominada Timuvrukti, usada para o preparo do moquém - essa madeira é muito dura e resistente na queima. No fogo para maserenne miyavye os Palikur-Arukwayene utilizavam apenas a lenha Kawap, uma lenha boa e dura que na sua queima dá muito carvão e, por isso, era muito boa para maserenne miyavye.

Quando o morto é homem, a filha ou filho procura três tios para que fiquem como responsáveis do ritual funerário, mas se a pessoa morta é mulher então as responsáveis devem ser tias ou sobrinhas. As responsáveis repassavam para os maridos o trabalho para preparar a fogueira para maserenne miyavye. O marido delas convidava outros homens para ajudar a realizar o masaraki. Porém, o senhor Wetmin disse que quem deveria acender o fogo deveria ser a filha ou filho caçula do morto, que ficava junto com ele na sua casa, até chegar o filho mais velho. Depois os netos também colocavam cinco lenhas na fogueira para maserenne miyavye.

\footnotetext{
${ }^{18}$ Maygukune são seres sobrenaturais capazes de fazer mal às pessoas. Essa designação é dita pelos mais velhos, enquanto as pessoas mais novas os conhecem como Watyebu.

${ }^{19}$ Expressão vulgarmente traduzida como "assar o morto". Contudo, não abrange todas as dimensões rituais do processo.

${ }^{20}$ Expressão vulgarmente traduzida como "assado". Contudo, não abrange todas as dimensões rituais do processo.

MARTINS, Zélia; MARTINS, Irabete; BENVEGNÙ, Vinícius Cosmos. Do maserenne miyavye ao enterro cristão: narrativas da morte Palikur-Arukwayene. Espaço Ameríndio, Porto Alegre, v. 14, n. 2, p. 326-345, jul./dez. 2020.
} 
Este artigo não ambiciona uma discussão simbólica aprofundada dos processos mortuários Palikur, senão, antes, um relato etnográfico. Contudo, a literatura etnológica é repleta de reflexões sobre rituais funerários dos povos indígenas na América dos Sul que se assemelham ao dos Palikur e podem dar mais subsídios para essa discussão. Manuela Carneiro da Cunha (1978), com Os Mortos e os Outros, apresenta as relações que os Krahô estabelecem com seus mortos e como isto configura a sua organização social. Aparecida Vilaça (1991) em sua etnografia com os Wari' descreve seu ritual funerário de endocanibalismo, onde o corpo do morto, após alguns dias de putrefação, é assado e consumido pelos seus parentes. Cecília McCallum (1996) discute os processos de morte e condição de pessoa entre os Kaxinawá. Seu argumento axial é que a morte e o exocanibalismo Kaxinawá se inserem em um ciclo de "produção consumptiva" de pessoa.

Dona Kusiksi relatou que após o ritual do maserenne miyavye cada família pegava os restos da pessoa falecida e colocava dentro de urnas funerárias feitas de argila e cinzas da casca da árvore kwep. Antigamente todas as pessoas já tinham urnas, de todos os tamanhos, preparadas em suas casas. É importante destacar que as urnas também tinham as marcas do clã a que pertencia o morto. Isso designava o local onde ocorreria o enterro, ou seja, próximo aos demais parentes. Os Palikur-Arukwayene enterravam seus mortos separados conforme a classificação dos clãs. $\mathrm{O}$ enterro por divisão clânica é uma prática dos antigos e que ainda hoje é respeitada e seguida estritamente. Isso acontece para que os clãs não se misturem, nem mesmo depois da morte.

Conforme os relatos do senhor Wetmin, muitos anos atrás o povo Palikur-Arukwayene morava numa aldeia chamada Kwap, localizada na margem esquerda do Rio Urucauá. O Kwap é hoje o cemitério do povo Palikur-Arukwayene, que se constituiu pelo fato de ter sido o local da guerra entre os Palikur-Arukwayene e os Hiyer. Por isso é comum que quando são cavadas as sepulturas nesse sítio sempre são encontrados mukuw com diferentes formas e tamanhos com pertences do morto dentro das urnas.

\section{Os ritos fúnebres entre os Palikur-Arukwayene atualmente}

Nessa seção é apresentado um relato sobre como ocorrem os funerais atualmente nas aldeias Palikur-Arukwayene. O relato foi contado pelo senhor Bunet acerca de um caso específico de morte. Era sobre uma mulher chamada Wakawmin, do clã Wakavuniyano (pessoa de origem da formiga preta), que faleceu em 2018 . Logo após o falecimento o cacique avisou as outras aldeias através do rádio que havia acontecido algo muito triste naquele momento na aldeia Kumenê, o falecimento de dona Wakawmin. Logo, as cunhadas da falecida pediram outras senhoras para dar o banho no seu corpo. O banho foi dado apenas com água e depois trocaram-se suas roupas. O marido da falecida, juntamente com seus filhos e genros, pegou 
quatro tábuas de madeira para fazer um suporte para o corpo ser velado durante a noite.

Depois, a filha da falecida logo procurou duas pessoas, uma sobrinha e uma prima, para se responsabilizarem em cavar a terra para o enterro, além de serem responsáveis em levar o corpo para o enterro no cemitério Kwap. Quando as mulheres são escolhidas para serem responsáveis do enterro, elas repassam esse trabalho para seus maridos. Os maridos, por sua vez, convidam outros homens para ajudá-los a cavar a sepultura e a levar o corpo para o enterro. Elas também convidam outras mulheres para, em sua presença, preparar os alimentos e servir bugunhak ${ }^{21}$ acompanhado com pimenta verde ${ }^{22}$, enquanto os homens trabalham.

Seu Bunet disse que quando Wakawmin faleceu, muitas pessoas de outros clãs vieram das aldeias vizinhas para passar a noite junto com a família da falecida. Também foram designados homens responsáveis para construir o caixão de madeira, que, por sua vez, também convidavam mais pessoas para ajudar. Então, enquanto os homens construíam o caixão, os jovens, homens e mulheres, que também foram escolhidos, se responsabilizaram em preparar os alimentos e servir tanto as pessoas que estavam trabalhando quanto aquelas que estavam passando a noite com a família da falecida.

Quando os homens terminaram de construir o caixão, logo as mulheres depositaram o corpo da falecida dentro. À meia-noite, a família da mulher falecida pediu para que as pessoas saíssem um pouco, para que os familiares ficassem velando o corpo e para a família fazer alguns iveyti kiverene myaviye para guardar dentro do caixão e também passar em cima do corpo. Os iveyti kiverene myaviye são colocados em cada extremidade do corpo - um fica na parte da cabeça, dois ficam nos ombros, dois ficam nos pés - e servem para proteger o corpo da falecida dos Ugukenbu ${ }^{23}$. Eles não deixam os Ugukenbu se aproximarem do corpo do morto ${ }^{24}$. O iveyti kiverene myaviye é feito de frutos de meksenvye seyne, sithu gayak, takesta assada, e deve ser guardado no pequeno pote de cerâmica ou de cabaça antes do amanhecer. O senhor Bunet disse que se enterrar o caixão sem

\footnotetext{
${ }^{21}$ Bebida, também conhecida como chibé, em que é servida farinha de mandioca com água acompanhada de pimenta e sal. Consumida em grandes cuias em atividades coletivas como mutirões, enterros, reuniões, assembleias etc.

${ }^{22}$ Comer com pimenta serve para proteger as pessoas que vão ao enterro, prevenindo que ao retornarem para suas casas o ganuwap do morto não retorne junto e ataque crianças e principalmente recém-nascidos, o que poderia levá-los ao adoecimento e, consequentemente, ao eventual falecimento.

${ }^{23}$ Ser sobrenatural que após o enterro pode se transformar em qualquer animal da floresta e cavar a sepultura do morto para comer seu corpo. Caso isso acorra, irá impedir que o morto cumpra sua passagem para o Pahakap, pois o morto depois de enterrado vai para o Pahakap e lá irá auxiliar o Kusuvwi, a mãe da chuva, a espalhar a água, encher os rios e possibilitar a abundância de peixes no rio.

${ }^{24}$ Ao lavarem o corpo do morto com ervas, os Ugukenbu não podem entrar no corpo do morto, pois o morto está com cheiro das ervas. O Ugukenbu não gosta do cheiro das ervas, e, além disso, ao lavar o corpo do morto com essas ervas impede que os Ugukenbu visualizem o corpo do morto. É por isso que sempre se lava o corpo do falecido antes de passar a noite com ele. $\mathrm{O}$ banho do morto ainda continua sendo feito. Até hoje quando uma pessoa morre lava-se o corpo e logo troca-se a roupa e veste-o com outra roupa limpa.
}

MARTINS, Zélia; MARTINS, Irabete; BENVEGNÙ, Vinícius Cosmos. Do maserenne miyavye ao enterro cristão: narrativas da morte Palikur-Arukwayene. Espaço Ameríndio, Porto Alegre, v. 14, n. 2, p. 326-345, jul./dez. 2020. 
passar iveyti kiverene myaviye no corpo do morto, os Ugukenbu podem se aproximar e fazer mal ao ganuwap do morto. Os Palikur-Arukwayene anciões dizem que quando uma pessoa morre seu ganuwap ainda está perto do corpo e, por isso, deve ser protegido contra os maygukune que querem fazer mal a ele.

Antigamente os Palikur-Arukwayene não conheciam o deus cristão, mas eles tinham os deuses como a lua, o sol, as nuvens, o vento e o trovão. Quando uma pessoa morria, ela passava a morar na lua ou nas nuvens, mas se o falecido havia cometido muitos erros durante sua vida na terra então nem a lua nem a nuvem aceitavam seu ganuwap. Cabia então ao vento e ao trovão aceitarem o ganuwap do morto. Mas, neste caso, o morto deveria pagar por todos os erros que cometeu, e, então, aonde o vento fosse ele deveria ir junto. Se o vento fosse para o mar fazendo grandes ondas, ele estaria no meio. Se o vento fosse em direção a montanha e batesse nas grandes árvores, o ganuwap do morto também bateria no tronco ou nos galhos. Ganuwap do morto sofria muito e nesses momentos pagaria por todos os erros que ele cometeu em vida. O vento e o trovão decidiriam se o morto já teria pago por todos seus erros. Então, o ganuwap do morto passaria para uma chuva forte com bastante trovão e muito barulho, pois na chuva os mortos passariam a tomar o banho para limpar ganuwap de todos os erros que cometeu em vida. Depois disso, então, passaria a morar na lua ou nas nuvens. Quando as nuvens a acalmassem ao final da tarde poder-seia ver o ganuwap sentado no meio das nuvens.

Hoje, contudo, o povo Palikur-Arukwayene adotou a religião cristã. Atualmente se uma pessoa morre, e se ele ou ela é de religião cristã, os pastores reúnem todos os membros da igreja na casa do morto para homenagear e fazer culto de orações com músicas por toda a noite. Antes de levar o corpo, todas as pessoas se reúnem perto do corpo para fazer oração e pedir ao deus cristão para receber o espírito do falecido, para que fique com ele no céu. Inclusive, se a falecida for mulher, os membros da igreja cantam a música em que a falecida lhes falaria: "irmãs não fiquem tristes, Deus mesmo me levou, creem em Deus que um dia nos veremos no céu". ${ }^{25}$

Mesmo tendo adotado outra religião, os Palikur-Arukwayene não deixam de praticar a cultura dos seus antepassados. Na cultura do povo Palikur-Arukwayene quando uma pessoa morre, toda a sua família ou clã entra em verdadeiro luto. Por exemplo, se o morto é do clã Wakavuyene, então todas as pessoas do clã Wakavuyene não podem ir à roça, as famílias devem ficar na casa até completar trinta dias, para depois poderem ir para roça, sair para pescar, caçar. Porque se uma pessoa do mesmo clã morre, sabe-se que se as famílias do morto saem para a roça, a plantação de itens

\footnotetext{
${ }^{25}$ Em sua etnografia Vallot (2017, p. 116) comenta sobre os Palikur e o encontro colonial na região do Rio Oiapoque, "Ao longo de sua história de contato com os brancos, os Palikur tiveram relações com diversos agentes ocidentais, mas foi somente a partir das políticas assimilacionistas do Estado [francês] e do contato com missionários que eles começaram a ter sua vida profundamente transformada (grifos nossos)". 
como mandioca, batata doce, macaxeira, bananeiras pode morrer toda, porque o ganuwap do morto pode fazer mal às plantas. O senhor Bunet explicou que quando seu avô faleceu, logo em seguida começou a faltar farinha e seus pais resolveram ir para a roça para tirar a mandioca para fabricar a farinha. No mesmo ano morreu toda a mandioca e a família perdeu a roça. Da mesma forma, a família do morto não pode sair para nenhum lugar distante sob risco de poder adoecer e morrer, pois o ganuwap do morto ainda está rodeando entre eles e querendo fazer mal a eles.

Após o corpo do morto já ter sido enterrado, os parentes ficam juntos na casa do falecido, e eles preparam alguns iveyti para afastar os maygukune para que não os incomodem durante a noite e o dia. A família queima o breu natural extraído da mata e mistura com pelo de macaco guariba e cuamba. Todas as pessoas que foram ao enterro devem passar por essa fumaça para afastar o espírito do morto. Também pegam folhas de marajá, que tem muitos espinhos, para varrer ao redor da casa em direção à beira do rio, onde o corpo foi embarcado para o enterro. Por fim queima-se tih, e então a pessoa rodeia a casa varrendo e dizendo: "Madikte amnapti maygukune mbayavyembu pesbet ,ka ik adah danukwa givinekut hiyeg gihiyekni"26. Quando o ganuwap do morto chegar ao redor da casa, ele não pode entrar nela, nem na casa das outras pessoas que ele conhecia quando estava vivo, nem pode andar ao redor da casa porque tem medo de espinhos e não consegue visualizar a casa. Então, sai dos arredores da casa e nunca mais volta para incomodar a família ou os parentes.

A senhora Agaykwa Minret, do clã Wayvroyano, também foi uma das interlocutoras que nos falou sobre o ritual funerário. Antigamente ela morava na aldeia Urubu, mas quando os pais dela faleceram, ela e o marido resolveram morar na aldeia Puwaytyeket. Minret contou que antigamente, no costume do povo Palikur-Arukwayene, quando uma pessoa falecia, todas as pessoas que iam ao velório, ao voltarem, antes de entrar na casa, tinham que tomar banho para afastar o maygukune que causa a morte. Se não tomasse banho ele entrava junto com ela na casa. As pessoas que levavam o corpo para o enterro e as pessoas que cavavam a terra, quando enterravam o corpo, todas elas também tinham que pegar um pouco de terra e jogar em cima do morto para se despedir da pessoa morta, e falavam juntos para o morto com toda tristeza: kugin pis usakwa ayin, kaba uhawkanakvwima.usuh ikisewp ayin amuh ini iwethit, ku kiney yuhmah pahavwinahma usekwekerevye ku aysaw ivegnete, henneme ahawkanahvwik myaka waxwap atanin . ineki ken amowkan pis amava inin iwethit. Kuriy usakwa ayin ka ba atak mwavunahma, usuh medbaki tivik dyuhen uvinekute ${ }^{27}$. Isso ainda continua sendo feito e dito nos enterros atuais.

\footnotetext{
${ }^{26}$ Todos os espíritos maus devem sair, e não podem aproximar da casa de alguém conhecido.

27 Agora você fica aqui, não é nossa culpa que a gente deixa você aqui nesse local, onde ninguém quer ficar quando a gente está vivo, mas foi a morte que levou você até aqui. Por isso você deve aceitar este lugar. Agora fique aqui e não vá em outros lugares, nós já vamos voltar para nossa casa.

MARTINS, Zélia; MARTINS, Irabete; BENVEGNÙ, Vinícius Cosmos. Do maserenne miyavye ao enterro cristão: narrativas da morte Palikur-Arukwayene. Espaço Ameríndio, Porto Alegre, v. 14, n. 2, p. 326-345, jul./dez. 2020.
} 
O esquecimento dos mortos é um elemento central na organização social de muitos povos indígenas da América do Sul. O esquecimento imperativo do morto é a condição para que os vivos possam continuar vivendo. Carneiro da Cunha comenta sobre o esquecimento entre os Krahô e outro povos jê:

a partida para o mundo dos mortos assemelha-se à passagem para o campo adverso, quando não a uma traição. Como em tantas outras sociedades [...] os parentes recriminam o defunto por tê-los abandonado, ao mesmo tempo que o exortam a se esquecer dos seus. O corte deve ser consumado e, para tanto, oferece-se ao karõ faminto uma derradeira refeição e se o contenta uma última vez com o ritual de encerramento do luto (CARNEIRO DA CUNHA, 2009, p. 65).

Eduardo Nunes em estudo com os Karajá de Buridina, também vai nessa direção ao afirmar que "lembrar dos mortos direciona o processo no sentido inverso, colocando, assim, o parentesco, i.e., a humanidade, em risco" (NUNES, 2012; p. 186), ou seja, para os Karajá de Buridina esquecer dos mortos é condição para que a vida, e, no limite, a humanidade estejam resguardadas.

Minret disse também que antigamente quando a pessoa morria a família devia tomar banho de madrugada até completar dez dias para se proteger da morte. Enquanto ela explicava sobre o costume do povo PalikurArukwayene no passado, de acordo como ela viveu com sua família, nós Uvayan e Kwaygu, nos recordamos de nossa mãe, na época em que morávamos na beira do rio, em frente a ilha Plutvinwa. Durante uma época, nossa mãe fazia a mesma coisa, acordava todos nós para tomarmos banho às cinco horas da madrugada até completar dez dias. Na época nós não entendíamos isso, pois éramos crianças, mas depois ficamos sabendo que naquela época havia morrido nossa avó e uma tia.

\section{CONSIDERAÇÕES FINAIS}

Esta não é uma seção que encerra o trabalho, mas, antes, visa deixar caminhos a percorrer, dos quais destacam-se três principais. Primeiramente, o texto apresenta um relato etnohistórico do processo mortuário do povo Palikur que pode (e deve) ser aprofundado à guisa da literatura e das discussões da etnologia indígena sul-americana sobre o tema. $O$ escopo aqui foi o registro de um conhecimento que vem se transformando entre os Palikur. O segundo caminho refere-se a outras formas de escrita acadêmica que decorrem da inserção de indígenas na universidade. Dois são os desafios. O primeiro, simetrizar conhecimentos pautados na oralidade, que são agora postos no papel, por pesquisadoras e pesquisadores indígenas que têm no português sua segunda ou terceira língua. O segundo decorre 
do exercício aqui proposto. Como escrever textos acadêmicos colaborativos entre indígenas e não indígenas sem que a voz dos indígenas seja apenas uma voz informativa. Em decorrência disso, destaca-se o desafio da autoria e do protagonismo indígena e seus desafios. Os parágrafos finais são dedicados a essa reflexão e foram exclusivamente feitos pelas autoras indígenas.

Reservamos este espaço de considerações finais para que nós Uvayan e Kwaygu pudéssemos tecer alguns comentários sobre a importância do trabalho de novas pesquisadoras indígenas. Nosso trabalho de conclusão de curso e este artigo são trabalhos que visam contribuir com as discussões acadêmicas sobre povos indígenas no Brasil que vêm sendo produzidos por pesquisadores não indígenas. O curso de Licenciatura Intercultural Indígena nos permitiu não somente compreender a importância de valorizar nossos conhecimentos e identidades, como também trabalhá-los no contexto da educação indígena diferenciada. Contudo, isso não significa que esses conhecimentos estavam esquecidos entre nós e agora passamos a resgatálos. O povo Palikur-Arukwayene, através dos seus mitos, explica os fatos que cercam a vida e a morte. A cosmologia revela o sistema simbólico vivenciado pela sociedade em toda a vida cotidiana. Elementos que nos possibilitam praticar os rituais funerários de acordo com nossos conhecimentos.

Antes do desenvolvimento da nossa pesquisa, nós já conhecíamos sobre os rituais funerários. Nossos pais sempre nos contavam como os antepassados enterravam nossos mortos. A licenciatura indígena despertou o interesse em aprofundar e conhecer mais sobre estas narrativas orais, além de organizá-las em narrativas escritas, para resguardar nosso patrimônio material e imaterial. Dessa forma, apresentamos aqui a importância da morte para o nosso povo.

Nós acreditamos que, quando uma pessoa morre, ela não morreu definitivamente, apenas está passando para o mundo dos mortos, o Pahakap. Nesse processo seu ganuwap ainda está circulando no meio da família. Por isso, as famílias cuidam dos rituais funerários para agradar o morto, para que ele tenha uma boa passagem para o Pahakap. Procuramos também entender como os antigos organizavam o enterro e como essa prática se transformou com o contato colonial. Anteriormente, o pajé era uma figura central para o povo. Era ele quem realizava curas através de contato com os maygukune, conduzia e organizava nossa vida cotidiana. No entanto, o povo Palikur-Arukwayene já não realiza o ritual funerário nem faz mais a Kayka Kisepka. Estas práticas foram transformadas pela influência das culturas não indígenas. Para eles, estas festas eram (e ainda são) vistas negativamente, e o pajé e seus os trabalhos entendidos como "pessoas do mal".

Gostaríamos também de destacar nosso lugar de fala enquanto mulheres indígenas e pesquisadoras. A maioria das pesquisas indígenas 
ainda está sendo feita por indígenas homens, fato que não deixa de ser importante, mas que deixa lacunas. Muitos conhecimentos e práticas do mundo indígena são preferencialmente do mundo das mulheres - a cerâmica funerária Palikur-Arukwayene é um exemplo. Sabemos que muitos dos conhecimentos e histórias que estão nesse trabalho foram possíveis porque éramos nós mulheres indígenas que estávamos pesquisando com outras mulheres indígenas.

Para finalizar, enfatizamos que, embora os rituais funerários tenham se transformado, a organização, as regras e prescrições continuam. Os saberes dos nossos antepassados continuam sendo transmitidos e fazem parte da cultura dos clãs Palikur-Arukwayene. Ademais, acreditamos que este é um espaço que se abre para que nós pesquisadoras e pesquisadores indígenas possamos apresentar, escrever e analisar nossos próprios sistemas simbólicos e cosmológicos. Pois é a partir de nossas vozes que queremos que os não indígenas nos conheçam. 
Espaço Ameríndio

\section{Referências documentais}

BUNET, Bonifácio Ioiô. Entrevista realizada em 10 de agosto de 2018, Aldeia Kumenê. Oiapoque/AP, Brasil.

KUSIKSI, Elheono Ioiô. Entrevista realizada no dia 02 de março de 2018, Aldeia Puwaytyeket. Oiapoque/AP, Brasil.

KAGUVRA, Jovita Labontê. Entrevistas e conversas realizadas em 2018, Aldeia Kumenê. Oiapoque/AP, Brasil.

MINRET, Verônica Ioiô. Entrevista realizada no dia 21 de agosto de 2018, Aldeia Kumenê. Oiapoque/AP, Brasil.

PAWANNAH, Matilde. Entrevista realizada no dia 20 de julho de 2018, Aldeia Yuwvwi (Pativye). Guiana Francesa.

SARISI, Davi Ioiô. Entrevista realizada no dia 01 de julho de 2018, Aldeia Maxika. Guiana Francesa.

WETMIN, Manuel Antônio dos Santos. Entrevista realizada no dia 13 de março de 2018, Aldeia Mangue. Oiapoque/AP, Brasil. 


\section{Referências bibliográficas}

BATISTA, Ramiro Esdras Carneiro. Keka Imawri: narrativas e códigos de guerra entre os Palikur-Arukwaynne. Belém, PPGA, 2019. Dissertação (Mestrado em Antropologia) Programa de Pós-Graduação em Antropologia, Universidade Federal do Pará, Belém, 2019.

CAPIBERIBE, Artionka. Batismo de fogo: os Palikur e o cristianismo. São Paulo, Annablume; Fapesp; Nuti, 2007.

CARNEIRO DA CUNHA. Manuela. Escatologia entre os Krahô. In: Cultura com aspas e outros ensaios. São Paulo: Cosac Naify, 2009.

GREEN, Lesley; GREEN, David. As esculturas das estrelas das chuvas: astronomia do Rio Urucauá. In: A presença do invisível: vida cotidiana e ritual entre os povos indígenas do Oiapoque. Lux Boelitz Vidal; José Carlos Levinho; Luís Donisete Benzi Grupioni (Org.) Rio de Janeiro, Iepé; Museu do Índio, 2016.

MARTINS, Zélia; MARTINS, Irabete. Kayka Kisepka: O Ritual Funerário do Povo Palikur. Oiapoque: CLII, 2019. Trabalho de Conclusão de Curso (Licenciatura Intercultural Indígena) - Curso de Licenciatura Intercultural Indígena, Universidade Federal do Amapá, Oiapoque, 2019.

MCCALLUM, Cecilia. Morte e pessoa entre os Kaxinawá. Mana, Rio de Janeiro, v. 2, n. 2, 1996.

NUNES, Eduardo, S. Lembrar dos vivos, esquecer dos mortos: Parentesco e memória entre os Karajá de Buridina (Aruanã - GO). In: Etnologia Indígena e Indigenismo / Org., José Pimenta, Maria Inês Smiljanic. - Brasília: Positiva, 2012.

VALLOT, Hugues Dominique. A colônia esquecida e a república assimilacionista: representações, políticas indigenistas e reivindicações indígenas na Guiana Francesa. Dissertação (Mestrado em Antropologia Social) - Programa de Pós-Graduação em Antropologia Social, Universidade Federal de Brasília, Brasília, 2017.

VILAÇA, Aparecida. Fazendo corpos: reflexões sobre morte e canibalismo entre os Wari' à luz do perspectivismo. Rev. Antropol., São Paulo, v. 41, n. 1, 1998.

VIVEIROS DE CASTRO, Eduardo. Os pronomes cosmológicos e o Perspectivismo Ameríndio. Mana, Rio de Janeiro, v. 2, n. 2, 1996.

WAKAVUNIYENE, Ailton Batista. Origens dos Clãs Palikur-Arukwayene: Kinetihwakri Amin Ku Karintak Arukwayene Himaw. Oiapoque: CLII, 2018. Trabalho de Conclusão de Curso (Licenciatura Intercultural Indígena) - Curso de Licenciatura Intercultural Indígena, Universidade Federal do Amapá, Oiapoque, 2018. 
Espaço Ameríndio

Recebido em: 19/06/2020 * Aprovado em: 04/12/2020 * Publicado em: 16/12/2020 